$\xi=-$ 国

\title{
Formation Algorithms and Properties of Binary Quasi-Orthogonal Code Sequence of Modern Satellite Systems
}

\author{
Vladimir Petrovich Pashintsev ${ }^{1}$, Igor Anatolyevich Kalmykov ${ }^{1}$, Aleksandr Pavlovich Zhuk ${ }^{1}$, Dmitrii Viktorovich \\ Orel $^{1}$, Elena Pavlovna Zhuk ${ }^{1}$ \\ ${ }^{1}$ North-Caucasus Federal University, Stavropol, 355009 Russia
}

\begin{abstract}
Increased number of threats to user interface of navigation signals, mainly in the form of suppression of navigation signals by jamming as well as navigation signal spoofing by false signals, assumes development of counter measures including improvement of structure security of navigation signals on the basis of stochastic use of code sequences which are ranging codes. This article proves the required number of unique discrete code sequences which can improve structure security of navigation signal in global navigation satellite system upon their stochastic use. Properties of discrete quasi-orthogonal code sequences are estimated which are used and proposed for use in global navigation satellite systems with channel code division, they are compared with optimum values of code balancing, number of element series and lower bounds of maximum lateral peaks of aperiodic auto-correlation function and maximum peaks of aperiodic mutualcorrelation function. The experimental results show that the minimum values of the considered correlation functions of discrete quasiorthogonal code sequences of known global navigation satellite systems exceed the lower bound by 3-6 times. The performances of code balancing and element series of discrete quasi-orthogonal code sequences of the known global navigation satellite systems satisfy in average the allowable intervals. The number of source lines of discrete quasi-orthogonal code sequences of the known global navigation satellite systems is significantly lower than their umber required for improvement of structure security of navigation signal based on their stochastic use. On the basis of the revealed drawbacks of the known discrete quasi-orthogonal code sequences, the necessity to develop new methods is substantiated allowing to obtain their required number together with statistic properties comparable with the best values of discrete quasiorthogonal code sequences applied as navigation signals in global navigation satellite systems.
\end{abstract}

Keywords: Global navigation satellite systems with code channel division; structure security of navigation signals; stochastic use of binary quasi-orthogonal code sequences.

\section{Introduction}

Technologies of positioning and timing support based on global navigation satellite systems (GNSS) become more and more popular in various fields of human life. Many countries develop their own GNSS: in addition to Russia and the USA with already developed GNSS, the European Union and China initiated development of their own systems, India, Japan, and Taiwan are on the way to development of regional navigation systems and functional add-ons to GNSS.

Nowadays the scopes of applications of navigating and timing support (NTS) on the basis of GNSS are widely applied for various transport, power, telecommunications, information and other systems. According to data of the European GNSS Agency (GSA) [1], cumulative cost of marketed products based on GNSS NTS as main and auxiliary functions will reach $€ 233$ billion to 2020, and the net cost of the GNSS NS receivers will be $€ 163$ billion.

Analysis of threats to functions and estimation of error controlled interfaces of GNSS with code division multiple access (CDMA) defines the following threats as the most significant for user interface: suppression of navigations signals (NS) by jamming as well as NS spoofing by false signal $[2,3]$.

It is demonstrated [4-6] that jam resistance of NS with CDMA upon arrangement of imitating jamming and NS spoofing can be improved by structure security of NS on the basis of stochastic use of code sequences which are ranging codes.
Since modern GNSS use NS obtained by known methods, then an urgent issue exists to establish required number of binary quasiorthogonal code sequences (BQOCS), sufficient for improvement of structure security of GNSS NS upon their stochastic use, as well as analysis and comparison of BQOCS number which can be obtained on the basis of existing methods of their building.

This work is aimed at determination of digital bound of sufficient number of BQOCS, which can improve structure security of GNSS NS upon their stochastic use and estimate conformity between this requirement and number of BQOCS obtained by known methods.

\section{Methods}

It is well-known [7] that operation lifetime of navigation spacecraft (NSC), GLONASS-K series, reaches 15 years. Since the algorithm of BQOCS generation by on-board equipment remains unchanged for overall NSC lifetime, it is necessary that it would provide structure security of NS for this period. Hence, application of nonrepeated BQOCS by all GNSS orbital NSC during 15 years can be considered as sufficient performance improvement of GNSS NS structure security. Total authorized number of NSC in GNSS GLONASS orbit group is 24 units but can be expanded to 32 [8]. Taking into consideration signals from various GNSS augmentation systems, the required number of code sequences in each BQOCS can be increased to 50 similarly to interface control document (ICD) for GNSS Galileo [9]. Radiation time of each binary code sequence 
(BCS) is about $1 \mathrm{~ms}$ and the length of each BCS is from 4,095 to 10,230 elements [7].

Therefore, the required number of nonrepeated BCS which can improve structure security of GNSS NS upon their stochastic use is $A_{r}=2.3652 \cdot 10^{13}$, it is assumed to combine them in systems of 50 sequences in each BQOCS.

It should be mentioned that the set of specifications is applied to BQOCS required for their use in GNSS NS with CDMA. In particular, they should be characterized by good correlation properties. In order to obtain BQOCS with good correlation properties, it is required that the sequences are characterized by randomness. Code sequences are random since they satisfy the following properties [10]:

Balancing: in each BCS period the number of "1" differs from the number of "0" not more than by unity.

Series property: in BCS period the length of one half of "1" and " 0 " series is 1 , one quarter -2 , one eighth -3 , and so on until it is worth.

Autocorrelation property: if BCS is compared by elements with its any cyclic shift during period of the same BCS, then the number of coincidences differs from that of noncoincidences not more than by one. Result of BCS summation in absolute magnitude of 2 with its cyclic shift should also be a balanced BCS

Let us estimate total number of BCS characterized by balancing.

The number of BCS "1" elements is $n_{1}=\frac{N+1}{2}$, the number of "0" elements is $n_{0}=\frac{N-1}{2}$. Then, the number of BCS

characterized by balancing can be defined as combination of $\mathrm{N}$ by $n_{0}$, or of $\mathrm{N}$ by $n_{1}$.

Let us prove that the number of combinations of $\mathrm{N}$ by $n_{0}$ equals to that of $\mathrm{N}$ by $n_{1}$ :

$$
\begin{aligned}
& C_{N}^{n_{0}}=\frac{N !}{n_{0} !\left(N-n_{0}\right) !}=\frac{N !}{\left(\frac{N-1}{2}\right) ! \cdot\left(\frac{N+1}{2}\right) !}, \\
& C_{N}^{n_{1}}=\frac{N !}{n_{1} !\left(N-n_{1}\right) !}=\frac{N !}{\left(\frac{N+1}{2}\right) ! \cdot\left(\frac{N-1}{2}\right) !} .
\end{aligned}
$$

Since Eqs. (1) and (2) differ only by the order of terms in the nominator, then $C_{N}^{n_{0}}=C_{N}^{n_{1}}$. Then, the total number of BCS characterized by balancing is defined as follows:

$$
K\left(n_{1}\right)=C_{N}^{n_{1}}=C_{N}^{(N+1) / 2},
$$

In order to satisfy the series property [11], their total number in BCS should be about one half of the sequence length:

$$
\mu_{0} \approx 0.5(N+1) \text {, }
$$

where $\mathrm{N}$ is the length of BCS. The number of BCS with the preset series number is [11]:

$$
A_{\mu}=2 C_{N-1}^{\mu-1}=2 \frac{(N-1) !}{(\mu-1) !(N-\mu) !}
$$

where $\mu$ is the number of series in sequence, $\mathrm{N}$ is the sequence length.

In addition, BCS in BQOCS should have low peaks of correlation functions. Total number of BCS meeting the correlation requirements is limited and determined as follows [12]:

$$
A_{c f}=\sqrt{2 /(\pi N)} \cdot 2^{N}
$$

Table 1 summarizes the total number of BCS; the number of BCS characterized by balancing; the number of BCS characterized by series property; the number of BCS satisfying correlation requirements for the length of 4,095; 8,191 and 10,230 elements. Such lengths of BCS are intended for use in NS with CDMA GNSS GLONASS [13].

Table 1: BCS Satisfying Various Requirements

\begin{tabular}{cccc}
\hline \multirow{2}{*}{ Number of BCS S } & \multicolumn{3}{c}{$\boldsymbol{N}$} \\
\cline { 2 - 4 } & $\mathbf{4 , 0 9 5}$ & $\mathbf{8 , 1 9 1}$ & $\mathbf{1 0 , 2 3 0}$ \\
\hline $\begin{array}{c}\text { Total number of } \\
\text { BCS A }\end{array}$ & $5.22 \cdot 10^{1232}$ & $5.45 \cdot 10^{2465}$ & $3.44 \cdot 10^{3079}$ \\
\hline $\begin{array}{c}\text { Number of BCS } \\
\text { characterized by } \\
\text { balancing } A_{b}\end{array}$ & $6.5 \cdot 10^{1230}$ & $4.8 \cdot 10^{2463}$ & $1.35 \cdot 10^{3077}$ \\
\hline $\begin{array}{c}\text { Number of BCS } \\
\text { characterized by } \\
\text { series property } \\
A_{\mu}\end{array}$ & $6.5 \cdot 10^{1230}$ & $4.8 \cdot 10^{2463}$ & $1.35 \cdot 10^{3077}$ \\
\hline $\begin{array}{c}\text { Number of BCS } \\
\text { satisfying } \\
\text { correlation } \\
\text { requirements } \\
A_{c f}\end{array}$ & $6.5 \cdot 10^{1230}$ & $2.12 \cdot 10^{2461}$ & $2.14 \cdot 10^{3075}$ \\
\hline
\end{tabular}

It was concluded in [11] that probability of high lateral peaks of autocorrelation function (ACF) decreased when the number of series approached optimum value $\mu_{0}$. In its turn, BCS possessing optimum number of series were characterized at the same time by balancing. Then, it is possible to assume that there exists certain BCS set characterized simultaneously by all three properties: $A_{b \mu c f}=A_{b} \cap A_{\mu} \cap A_{c f}$ characterized simultaneously by all three approximately to the number of BCS satisfying the correlation requirements: $A_{b \mu c f} \approx A_{c f}$.

On the basis of the aforementioned and considering that $A_{r}<<A_{b \mu c f}$, it is possible to assume that there exists a number of BCS characterized by the required properties which would provide high level of structure security of GNSS NS during 15 years.

According to [10], it is assumed that BCS with $\{ \pm 1\}$ alphabet is characterized by good correlation properties when averaged absolute magnitudes of lateral peaks of aperiodic autocorrelation function (AACF) at all time shifts are close to $1 / \sqrt{N}$. However, more stringent estimation of BCS correlation properties is the absolute magnitude of maximum lateral AACF peak $R_{A}$. It is known that the maximum lateral AACF peak cannot be lower than the preset bound $R_{A} \geq 1 / \sqrt{N}$, where $\mathrm{N}$ is the length of BCS. The correlation properties of BCS are the better, the lower is the absolute magnitude of maximum lateral AACF peak.

In BQOCS together with ACF the cross correlation functions (CCF) of each BCS pair in BQOCS are highly important. In addition, for 
maximum peaks of aperiodic mutual correlation function (ACCF) there exists lower bound known as the Welch bound [14,15]. The lower bound of absolute magnitudes of maximum lateral ACCF peaks of BCS with $\{ \pm 1\}$ alphabet will be:

$$
R_{C} \geq \frac{\sqrt{N-\left[\frac{\pi N}{\sqrt{8 M}}\right\rceil}}{N} M \geq 5
$$

where $\mathrm{M}$ is the number of BCS in BQOCS, $\mathrm{N}$ is the length of BCS.

Table 2 shows lower bounds of absolute magnitudes of maximum lateral $\mathrm{AACF}$ and $\mathrm{ACCF}$ peaks for BQOCS containing $M=50$ BCS with the length of $\mathrm{N}=4095,8191$, and 10,230 elements. As can be seen in Table 2, the lower bounds of absolute magnitudes of maximum lateral AACF peaks and maximum ACCF peaks are close to each other and decrease with the BCS length and increase with the number of source lines. The shown values are the lower bound of maximum peaks of mutual correlation function.

Table 2: Lower Bounds Of Absolute Magnitude Of AACF Maximum Lateral Peaks And Maximum ACCF Peaks For BQOCS Of 50 Sequences

\begin{tabular}{lll}
\hline $\begin{array}{l}\text { BCS } \\
\text { length, N }\end{array}$ & $\begin{array}{l}\text { Lower bound of absolute } \\
\text { magnitude of AACF } \\
\text { maximum lateral peak, }\end{array}$ & $\begin{array}{l}\text { Lower bound of } \\
\text { absolute value of ACCF }\end{array}$ \\
& $R_{A}$ maximum peak, $_{c}$ \\
\hline 4,095 & 0.016 & 0.016 \\
\hline 8,191 & 0.011 & 0.011 \\
\hline 10,230 & 0.010 & 0.010 \\
\hline
\end{tabular}

It has been mentioned in [11] that in order to decrease root mean square value of mutual correlation function, the root mean square values of ACF should be decreased. Therefore, on the basis of a set of BCS with low maximum lateral AACF peaks, it is possible to obtain BQOCS with low ACCF peaks.

Lower bounds of absolute magnitudes of maximum lateral AACF peaks and maximum ACCF peaks are comparable with actual BQOCS properties. With this aim it is necessary to estimate the properties of BQOCS used and intended for use in GNSS with CDMA. Then it is required to compare them with the optimum values of code balancing, the number of element series, and the lower bounds of maximum lateral AACF peaks and maximum ACCF peaks.

\section{Results}

Only averaged data are available on AACF and ACCF peaks of BQOCS at all possible shifts and the data on code balancing and number of element series are not published. Herewith, absolute magnitudes of maximum lateral AACF peaks and ACCF peaks are highly important for estimation of correlation properties of BQOCS. The length of BCS used in NS is from 1,023 to 10,230 elements.

Table 3 presents main description of NS in operating and deploying GNSS. In order to estimate statistic properties of BQOCS used in GNSS in MATLAB environment, the software was developed [16] which buildt BQOCS for the NS summarized in Table 3 .

For each estimated BQOCS maximum absolute magnitudes of lateral AACF peaks for each BCS $r_{A}$ were determined as well as maximum absolute magnitudes of ACCF peaks of each BCS pair without repetitions $r_{C}$. On the basis of these data, maximum lateral AACF peaks $\max \left(r_{A}\right)$ and ACCF peaks $\max \left(r_{C}\right)$ were determined as well as averaged $m\left(r_{A}\right)$ and $m\left(r_{C}\right)$ respectively [17].
Table 3: GNSS Navigation Signals GLONASS navigation signals

\begin{tabular}{|c|c|c|c|c|}
\hline \multicolumn{5}{|c|}{ GLONASS navigation signals } \\
\hline NSC type & $\begin{array}{c}\mathrm{G} 1 \\
(1,575.42 \\
\mathrm{MHz}) \\
\end{array}$ & $\begin{array}{c}\mathrm{G} 2(1,242 \\
\mathrm{MHz})\end{array}$ & $\begin{array}{c}\text { G3 } \\
(1,207.14 \\
\text { MHz }) \\
\end{array}$ & $\begin{array}{c}\text { G5 } \\
(1,176.45 \\
\text { MHz }) \\
\end{array}$ \\
\hline $\begin{array}{c}\text { GLONASS- } \\
\mathrm{M}\end{array}$ & $\begin{array}{c}\text { L1OF, } \\
\text { L1SF }\end{array}$ & $\begin{array}{l}\text { L2OF, } \\
\text { L2SF }\end{array}$ & - & - \\
\hline $\begin{array}{c}\text { GLONASS- } \\
\text { K1 }\end{array}$ & $\begin{array}{l}\text { L1OF, } \\
\text { L1SF }\end{array}$ & $\begin{array}{l}\text { L2OF, } \\
\text { L2SF }\end{array}$ & L3OC & - \\
\hline $\begin{array}{c}\text { GLONASS- } \\
\text { K2 }\end{array}$ & $\begin{array}{l}\text { L1OF, } \\
\text { L1SF } \\
\text { L1OC, } \\
\text { L1SC } \\
\end{array}$ & $\begin{array}{l}\text { L2OF, } \\
\text { L2SF, } \\
\text { L2SC }\end{array}$ & L3OC & - \\
\hline $\begin{array}{c}\text { GLONASS- } \\
\text { KM }\end{array}$ & $\begin{array}{c}\text { L1OF, } \\
\text { L1SF } \\
\text { L1OC, } \\
\text { L1OCM, } \\
\text { L1SC } \\
\end{array}$ & $\begin{array}{l}\text { L2OF, } \\
\text { L2SF } \\
\text { L2OC, } \\
\text { L2SC }\end{array}$ & L3OC & L5OC \\
\hline \multicolumn{5}{|c|}{ Navstar GPS navigation signals } \\
\hline NSC series & $\begin{array}{c}\text { L1 } \\
(1,575.42 \\
\mathrm{MHz}) \\
\end{array}$ & $\begin{array}{c}\mathrm{L} 2 \\
(1,227.60 \\
\mathrm{MHz}) \\
\end{array}$ & $\begin{array}{c}\mathrm{L} 3 \\
(1,381.05 \\
\mathrm{MHz}) \\
\end{array}$ & $\begin{array}{c}\text { L5 } \\
(1,176.45 \\
\text { MHz) } \\
\end{array}$ \\
\hline GPS-IIR & $\begin{array}{l}\text { L1C/A, } \\
\text { L1P(Y) }\end{array}$ & $\mathrm{L} 2 \mathrm{P}(\mathrm{Y})$ & NDS & - \\
\hline GPS-IIR-M & $\begin{array}{c}\text { L1C/A, } \\
\text { L1P(Y), } \\
\text { L1M }\end{array}$ & $\begin{array}{c}\text { L2C, } \\
\text { L2P(Y), } \\
\text { L2M }\end{array}$ & NDS & - \\
\hline GPS-IIF & $\begin{array}{l}\text { L1C/A, } \\
\text { L1P(Y), } \\
\text { L1M }\end{array}$ & $\begin{array}{c}\text { L2C, } \\
\text { L2P(Y), } \\
\text { L2M }\end{array}$ & NDS & $\mathrm{L} 5 \mathrm{C}$ \\
\hline GPS-III & $\begin{array}{l}\text { L1C/A, } \\
\text { L1C, } \\
\text { L1P(Y), } \\
\text { L1M }\end{array}$ & $\begin{array}{l}\text { L2C, } \\
\text { L2P(Y), } \\
\text { L2M }\end{array}$ & NDS & $\mathrm{L} 5 \mathrm{C}$ \\
\hline \multicolumn{5}{|c|}{ Galileo navigation signals } \\
\hline NSC series & $\begin{array}{c}\text { E2-L1-E1 } \\
(1,575.42 \\
\text { MHz) }\end{array}$ & $\begin{array}{c}\text { E5 } \\
(1,207.14 \\
\text { MHz) }\end{array}$ & \multicolumn{2}{|c|}{ E6 $(1,278.75 \mathrm{MHz})$} \\
\hline FOC & E1 & E5a, E5b & \multicolumn{2}{|c|}{ E6 } \\
\hline \multicolumn{5}{|c|}{ BeiDou/COMPASS navigation signals } \\
\hline NSC series & $\begin{array}{c}\mathrm{E} 2 \\
(1,207.14 \\
\mathrm{MHz}) \\
\end{array}$ & $\begin{array}{c}\text { E5b } \\
(1,268.52 \\
\text { MHz) }\end{array}$ & \multicolumn{2}{|c|}{ E6 $(1,561.098 \mathrm{MHz})$} \\
\hline BeiDou-1 & B1 & B2 & & 33 \\
\hline
\end{tabular}

For all BCS the number of element series was determined as well as the number of "1" elements (code balancing). Maximum, minimum, and averaged number of series of BQOCS is denoted as $\max (\mathrm{S}), \min (\mathrm{S}), \mathrm{m}(\mathrm{S})$, respectively. Maximum, minimum, and averaged number of "1" elements for BQOCS is denoted as max(B), $\min (\mathrm{B})$, and $\mathrm{m}(\mathrm{B})$, respectively. Estimations of BQOCS of GNSS NS are summarized in Table 4.

Table 4: Statistic Properties Of BQOCS Used In GNSS With CDMA

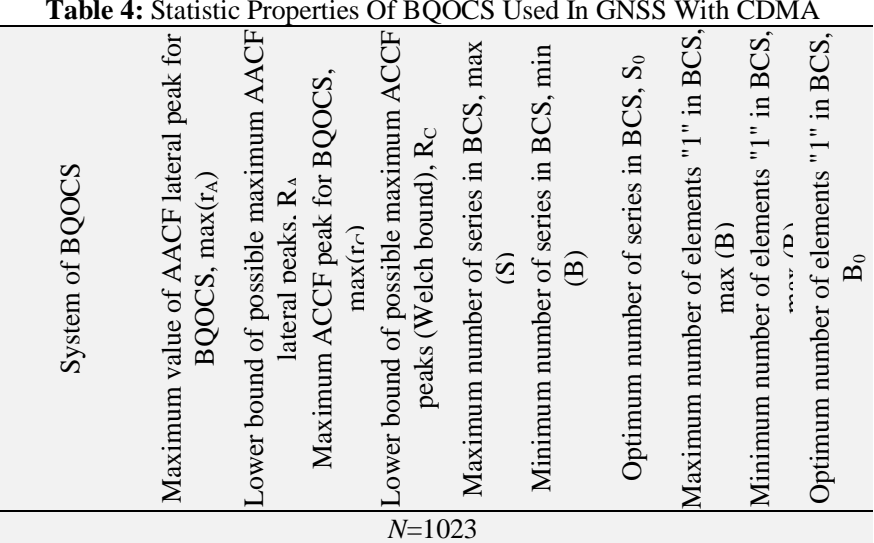

\begin{tabular}{lllllllllll}
\hline GPS L1C/A & 0.095 & 0.03 & 0.99 & 0.031 & 545 & 480 & 512 & 544 & 480 & 512
\end{tabular}

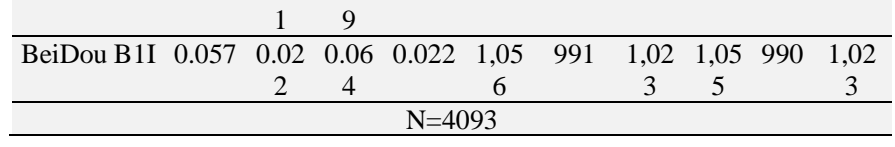




\begin{tabular}{|c|c|c|c|c|c|c|c|c|c|c|}
\hline Galileo E1- & 0.669 & 0.01 & 0.10 & 0.016 & 2,19 & 1,873 & 2,04 & 1,41 & 1,3 & 2,04 \\
\hline B & & 6 & 6 & & 7 & & 7 & 0 & 23 & 7 \\
\hline Galileo E1- & 0.287 & 0.01 & 0.10 & 0.016 & 2,12 & 1,978 & 2,04 & 2,00 & 1,9 & 2,04 \\
\hline $\mathrm{C}$ & & 6 & 7 & & 2 & & 7 & 1 & 08 & 7 \\
\hline \multicolumn{11}{|c|}{$\mathrm{N}=10230$} \\
\hline GPS & 0.029 & 0.01 & 0.99 & 0.010 & 5,11 & 5,117 & 5,11 & 5,11 & 5,1 & 5,11 \\
\hline $\mathrm{L} 1 \mathrm{C}(\mathrm{P})$ & & 0 & 9 & & 9 & & 5 & 5 & 14 & 5 \\
\hline GPS & 0.028 & 0.01 & 0.99 & 0.010 & 5,11 & 5,117 & 5,11 & 5,11 & 5,1 & 5,11 \\
\hline L1C(D) & & 0 & 9 & & 9 & & 5 & 5 & 14 & 5 \\
\hline GPS & 0.525 & 0.01 & 0.49 & 0.010 & 5,23 & 4,972 & 5,11 & 5,24 & 4,9 & 5,11 \\
\hline $\mathrm{L} 2 \mathrm{C}(\mathrm{CM})$ & & 0 & 9 & & 6 & & 5 & 1 & 66 & 5 \\
\hline \multirow[t]{2}{*}{ GPS L5(I) } & 0.033 & 0.01 & 0.19 & 0.010 & 5,20 & 5,003 & 5,11 & 5,21 & 4,9 & 5,11 \\
\hline & & 0 & 9 & & 9 & & 5 & 7 & 98 & 5 \\
\hline \multirow[t]{2}{*}{ GPS L5(Q) } & 0.034 & 0.01 & 0.19 & 0.010 & 5,22 & 5,003 & 5,11 & 5,23 & 4,9 & 5,11 \\
\hline & & 0 & 9 & & 3 & & 5 & 8 & 87 & 5 \\
\hline Galileo & 0.040 & 0.01 & 0.04 & 0.010 & 5,25 & 4,996 & 5,11 & 5,46 & 5,0 & 5,11 \\
\hline E5a-I & & 0 & 7 & & 3 & & 5 & 0 & 07 & 5 \\
\hline Galileo & 0.039 & 0.01 & 0.05 & 0.010 & 5,28 & 4,928 & 5,11 & 6,40 & 4,2 & 5,11 \\
\hline E5a-Q & & 0 & 0 & & 3 & & 5 & 8 & 92 & 5 \\
\hline Galileo & 0.038 & 0.01 & 0.04 & 0.010 & 5,28 & 4,966 & 5,11 & 5,25 & 3,7 & 5,11 \\
\hline E5b-I & & 0 & 5 & & 8 & & 5 & 3 & 10 & 5 \\
\hline Galileo & 0.039 & 0.01 & 0.04 & 0.010 & 5,29 & 4,891 & 5,11 & 5,25 & 3,7 & 5,11 \\
\hline E5b-Q & & 0 & 9 & & 0 & & 5 & 4 & 03 & 5 \\
\hline GLONASS & 0.028 & 0.01 & 0.02 & 0.010 & 5,21 & 5,004 & 5,11 & 5,22 & 5,0 & 5,11 \\
\hline $\mathrm{L} 3 \mathrm{OC}(\mathrm{I})$ & & 0 & 8 & & 6 & & 5 & 1 & 05 & 5 \\
\hline GLONASS & 0.028 & 0.01 & 0.02 & 0.010 & 5,21 & 5,004 & 5,11 & 5,22 & 5,0 & 5,11 \\
\hline L3OC(Q) & & 0 & 8 & & 6 & & 5 & 1 & 05 & 5 \\
\hline
\end{tabular}

With the aim of comparison, the table also shows the lower bounds of possible maximum lateral $\mathrm{AACF}$ peaks and maximum $\mathrm{AACF}$ peaks as well as optimum number of element series and number of "1" elements.

\section{Discussion}

As follows from Table 4, the best maximum lateral AACF peaks and maximum ACCF peaks exceed lower bounds of respective indices by 3-5 times. Correlation properties of some BQOCS of NS exceed boundary values by multiple times which also can be mentioned as nonconformity with requirements.

The lowest values of maximum lateral AACF peaks are characteristic for BQOCS of NS in GPS L1C(D), GLONASS $\mathrm{L} 3 \mathrm{OC}(\mathrm{I})$, and $\mathrm{L} 3 \mathrm{OC}(\mathrm{Q})$. The lowest values of maximum ACCF peaks are also for BQOCS of NS in GLONASS L3OC(I) and L3OC(Q). Herewith, the best code balancing and the closest to optimum number of series was for BQOCS NS of GPS L1C(P) and L1C(D), though, similar properties of BQOCS NS of GLONASS L3OC(I) and L3OC(Q) were not inferior.

Strict conformity with the requirement of code balancing can be too strict for building high amount of BCS. Code balancing can be

estimated by the coefficient of imbalance

$$
d=\frac{\Delta N}{N}
$$

[9], where $\Delta \mathrm{N}$ is the difference in the ratio between "0" and "1": $\Delta \mathrm{N}=|\mathrm{S} 1-\mathrm{S} 0|$ and $\mathrm{N}$ is the length of BCS. In the BCS with optimum balance $\triangle \mathrm{N}$ $=1$. According to data in Table $4, \Delta \mathrm{N}$ of BCS with the best correlation properties reaches 111 , and $\mathrm{d}$, respectively, reaches 0.01 .

The number of series in BCS also can deviate from the optimum values. In [9] allowable limits of such deviation without significant influence on correlation peaks are defined as follows:

$$
\mu_{0}-\Delta \mu \leq \mu \leq \mu_{0}+\Delta \mu, \Delta \mu=\frac{\sqrt{N-1}}{2} \text { for } N>1
$$

Table 5 summarizes the intervals of allowable deviations of number of series and code balancing for BCS of various length.
Table 5: Intervals of allowable deviations of series number and code balancing

\begin{tabular}{|l|l|l|l|l|}
\hline$N$ & $\Delta \mu$ & $\mu_{0}$ & $\Delta N$ & $d$ \\
\hline 1,023 & 15 & 512 & 61 & 0.06 \\
\hline 4,095 & 31 & 2,048 & 82 & 0.02 \\
\hline 8,191 & 45 & 4,096 & 82 & 0.01 \\
\hline 10,230 & 50 & 5,115 & 101 & 0.01 \\
\hline
\end{tabular}

Since the number of BCS reserved for use in GNSS NS is in the range of 37-210, this is insufficient for improvement of structural security of NS.

Analysis of properties of BQOCS used and reserved for use in GNSS NS evidences as follows:

The lowest absolute magnitudes of maximum lateral AACF peaks and the lowest absolute magnitudes of maximum ACCF peaks of BQOCS in GNSS NS exceed the lower bound by 3-6 times, that is, equal to $0.03-0.06$.

The indices of code balancing and number of element series in BCS of GNSS NS are in average in the allowable intervals summarized in Table 5

The number of source lines of BQOCS used in GNSS NS does not exceed $210 \mathrm{BCS}$, which is significantly lower than the required number of BCS $A_{r}$ for improvement of NS jamming protection. The revealed drawbacks of the known BQOCS stipulate necessity of development of new methods allowing to obtain required amount of BQOCS $A_{r}$ characterized by statistic properties comparable with the best properties of BQOCS applied as NS in GNSS

\section{Conclusions}

Growing market of appliances and services using GNSS NTS as main and auxiliary functions predefines increase in threats for interfaces of navigation signals, mainly in the form of jamming of NS and NS spoofing by false signals.

Jam resistance of NS with CDMA upon arrangement of imitating jamming and NS spoofing can be improved by structure security of NS on the basis of stochastic use of code sequences which are ranging codes.

It is proved that the required number of unique BCS which can improve structure security of GNSS NS upon their stochastic use is $A_{r}=2.3652 \cdot 10^{13}$

This article presents total number of BCS; number of BCS characterized by balancing; number of BCS characterized by series property; number of BCS meeting correlation requirement for 4,$095 ; 8,191$, and 10,230 elements which are used or intended for use in NS with CDMA in GLONASS. Lower bounds of absolute magnitudes of maximum lateral peaks of AACF and ACCF are presented for BQOCS containing $\mathrm{M}=50 \mathrm{BCS}$ with the length $\mathrm{N}=$ 4,$095 ; 8,191$, and 10,230 elements.

Properties of BQOCS are estimated which are used or intended for use in GNSS with CDMA, they are compared with optimum values of code balancing, number of element series and lower bounds of maximum lateral peaks of AACF and maximum peaks of ACCF. With this aim for each estimated BQOCS, maximum absolute magnitudes of lateral AACF peaks for each BCS $r_{A}$ were determined as well as maximum absolute magnitudes of ACCF peaks of each BCS pair without repetitions $r_{C}$. On the basis of these data, maximum lateral AACF peaks $\max \left(r_{A}\right)$ and ACCF peaks $\max \left(r_{C}\right)$ were determined as well as averaged $m\left(r_{A}\right)$ and $m\left(r_{C}\right)$, respectively. 
The experimental results demonstrate that the lowest absolute magnitudes of maximum lateral AACF peaks and the lowest absolute magnitudes of maximum ACCF peaks of BQOCS of GNSS NS exceed the lower bound by 3-6 times. The indices of code balancing and number of element series in BCS of GNSS NS are in average in the allowable intervals. The number of source lines of BQOCS used in GNSS is significantly lower than their number A required for improvement of structure security of NS on the basis of their stochastic use.

The revealed drawbacks of the known BQOCS stipulate necessity of development of new methods allowing to obtain required amount of BQOCS $A_{r}$ characterized by statistic properties comparable with the best properties of BQOCS applied as NS in GNSS.

\section{Acknowledgements}

This work was supported by the Russian Foundation for Basic Research, project No. 18-07-01020.

\section{References}

[1] GSA GNSS Market 2012 http://www.gsa.europa.eu/sites/default/files/MarketReportMEP720 12WEB.PDF

[2] Dyatlov, A.P., Kul'bikayan, B.Kh. 2006. Radiomonitoring izluchenii sputnikovykh radionavigatsionnykh sistem: monografiya [Remote monitoring of radiations of satellite navigation systems: Monograph]. Moscow, Radio i svyaz'.

[3] Dyatlov, A.P., Dyatlov, P.A., Kul'bikayan, Kh. 2004 Radioelektronnaya bor'ba so sputnikovymi radionavigatsionnymi sistemami [Electronic warfare with satellite navigation systems] Moscow, Radio i svyaz'.

[4] Stepanov, S.A. 1987. O chisle neprivodimykh nad konechnym polem mnogochlenov zadannogo vida [On number of preset irreducible polynomial over finite field]. Matem. zametki, 41(3), 289-295.

[5] Scott, L. 2012. Spoofs, Proofs and Jamming. Inside GNSS, 5, 4253.

[6] Warner, J.S., Johnston, R.G. 2003. GPS Spoofing Countermeasures Homeland Security Journal, 8

[7] Urlichich, Yu.M., Subbotin, V.A., Stupak, G.G., Dvorkin, V.Z., Povalyaev, A.A., Karutin, S.N. 2011. Innovatsiya: GLONASS Strategii razvitiya [Innovations: GLONASS. Development strategies]. Sputnikovaya navigatsiya i KVNO. Overview, 2. IATs TsNIImash, 18-22.

[8] Perov, A.I., Kharisov, V.N. 2010. GLONASS. Printsipy postroeniya i funktsionirovaniya [GLONASS. Principles of arrangement and operation]. 4th edition, revised and supplemented. Moscow, Radiotekhnika.

[9] European GNSS (Galileo) Open Service Signal In Space Interface Control Document, 1. 2010.

[10] Golomb, S. 1967. Shift Register Sequences. San Francisco, HoldenDay.

[11] Varakin, L.E. 1978. Teoriya sistem signalov [Theory of signal systems]. Moscow, Sovetskoe radio.

[12] Kanevskii, Z.M., Litvinenko, V.P., Makarov, G.V., Maksimov, D.A 2006. Osnovy teorii skrytnosti: [Foundations of security theory. Guidebook]. Voronezh, VGU.

[13] Pchelintsev, A.P. 2008. Novye signaly GLONASS [New GLONASS signals]. On-line journal "Integrirovannye Sputnikovye Navigatsionnye Sistemy", 2, 4-6.

[14] Ipatov, V.P. 1992. Periodicheskie diskretnye signaly s optimal'nymi korrelyatsionnymi svoistvami [Periodic discrete signals with optimum correlation properties]. Moscow, Radio i svyaz'.

[15] Levenshtein, V.I. 1999. New Lower Bounds on Aperiodic Crosscorrelation of Binary Codes. IEEE Transactions on Information Theory, 1(45), 284-288.

[16] Orel, D.V., Zhuk, A.P., Ivanov, A.S. 2009. Generator of spreading sequences of navigation signals with estimation of correlation properties. Certificate of State registration of computer program № 2010610800.
[17] Orel, D.V., Zhuk, A.P. 2009. Issledovanie korrelyatsionnykh kharakteristik rasshiryayushchikh posledovatel'nostei signalov s kodovym razdeleniem kanalov sistem sputnikovoi radionavigatsii [Studying correlation properties of spreading sequences of signals with code division of radio navigation satellite systems]. Reshetnev Readings: Proceedings of 13 International Scientific Conference devoted to the $50 \mathrm{~h}$ Anniversary of Siberian State Aerospace University: in two parts. Krasnoyarsk, Siberian State Aerospace University, 1, 154-156. 